\title{
Recent trends in cardiovascular disease deaths: a state specific perspective
}

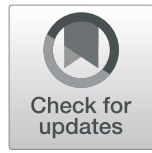

Sheila M. Manemann', Yariv Gerber ${ }^{1,2}$, Suzette J. Bielinski', Alanna M. Chamberlain', Karen L. Margolis³, Susan A. Weston ${ }^{1}$, Jill M. Killian ${ }^{1}$ and Véronique L. Roger ${ }^{1,4,5^{*}}$

\begin{abstract}
Background: The rate of decline in cardiovascular disease (CVD) mortality has lessened nationally. How these findings apply to specific states or causes of CVD deaths is not known. Examining these trends at the state level is important to plan local interventions.

Methods: We analyzed CVD mortality trends in Minnesota (MN) using the U.S. Centers for Disease Control and Prevention (CDC) Wide-ranging ONline Data for Epidemiologic Research (WONDER). Trends were analyzed by age, sex, type of CVD and location of death.

Results: CVD mortality rates in MN declined in 2000-2009 and then leveled off in 2010-2018, paralleling national rates. Age- and sex-adjusted CVD mortality decreased by 3.7\% per year in 2000-2009 (average annual percent changes [AAPC]: $-3.7 ; 95 \% \mathrm{Cl}$ - 4.8, - 2.6) with no change observed in 2010-2018. Those aged 65-84 years had the most rapid early decline in CVD mortality (AAPC: $-5.9,95 \% \mathrm{Cl}:-6.2,-5.7)$ and had less improvement in 2010-2018 (AAPC: $-1.8,95 \% \mathrm{Cl}:-2.2,-1.5$ ), and the younger age group (25-64 years) now experiences the most adverse trends (AAPC: 1.2, 95\% Cl: 0.7-1.8). Coronary heart disease (CHD) and cerebrovascular disease had the largest relative decreases in mortality in 2000-2009 (CHD AAPC: -5.2; 95\% Cl:-6.5,-3.9; cerebrovascular disease AAPC: -4.4, $95 \% \mathrm{Cl}$ : $-5.2,-3.6)$ with no change 2010-2018. Heart failure (HF)/cardiomyopathy followed similar trends with a 2.5\% decrease (AAPC 95\% Cl: - 3.5, - 1.5) per year in 2000-2009 and no change in 2010-2018. Deaths from other CVD also decreased in the early time period (AAPC: -1.6, 95\% Cl: $-2.7,-0.5)$ but increased in 2010-2018 (AAPC: 1.9, $95 \%$ Cl: $0.5,3.3)$. In- and out-of-hospital death rates improved in 2000-2009 with a slowing in improvement for inhospital death and no further improvement for out-of-hospital death in 2010-2018.

Conclusion: Concerning CVD mortality trends occurred in MN. In the most recent decade (2010-2018) mortality from all CVD subtypes plateaued or even increased. CVD mortality among the younger age groups increased as well. These data are congruent with adverse national trends supporting their generalizability. These adverse trends underscore the urgent need for CVD prevention and treatment, as well as continued surveillance to assess progress at the state and national level.
\end{abstract}

Keywords: Community surveillance, Cardiovascular disease, Epidemiology, Secular trend analysis

\footnotetext{
* Correspondence: roger.veronique@mayo.edu

'Department of Quantitative Health Sciences, Mayo Clinic, 200 First Street,

SW, Rochester, MN 55905, USA

${ }^{4}$ Department of Cardiovascular Diseases Medicine, Mayo Clinic, Rochester,

MN, USA

Full list of author information is available at the end of the article
}

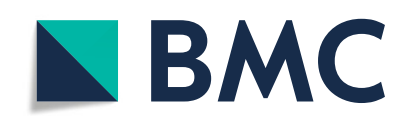

(C) The Author(s). 2021 Open Access This article is licensed under a Creative Commons Attribution 4.0 International License, which permits use, sharing, adaptation, distribution and reproduction in any medium or format, as long as you give appropriate credit to the original author(s) and the source, provide a link to the Creative Commons licence, and indicate if changes were made. The images or other third party material in this article are included in the article's Creative Commons licence, unless indicated otherwise in a credit line to the material. If material is not included in the article's Creative Commons licence and your intended use is not permitted by statutory regulation or exceeds the permitted use, you will need to obtain permission directly from the copyright holder. To view a copy of this licence, visit http://creativecommons.org/licenses/by/4.0/ The Creative Commons Public Domain Dedication waiver (http://creativecommons.org/publicdomain/zero/1.0/) applies to the data made available in this article, unless otherwise stated in a credit line to the data. 


\section{Introduction}

In the United States (US), total cardiovascular disease (CVD) mortality declined steadily between the 1970s and 2016 [1, 2]. The rising prevalence of obesity and diabetes mellitus (type 1 and 2) over the same period suggested that if these risk factors had been controlled, gains would have been even greater. Since the turn of the century, the burden of obesity and diabetes mellitus escalated in the US $[1,3]$ and worldwide $[4,5]$, raising the concern that CVD mortality gains would eventually stop. Recent national data also suggested that blood pressure control steadily improved from 1988 to 2010, reached a plateau until 2016, and declined substantially in 2017-2018 [6]. Against the backdrop of these adverse risk factor trends, in 2011, the number of deaths from all CVD, heart disease, and stroke in the US began increasing, resulting in a slow down in the decline of corresponding mortality rates. The increase in absolute number and age-adjusted rates of deaths due to CVD is a significant event, which marks the time when we started losing ground in the fight against heart disease.

Partitioning of the causes of death revealed striking heterogeneity as the decline continued for ischemic heart disease, while age-adjusted rates of deaths from heart failure (HF) actually reversed from a downward to a rising trend [7]. These critically important reports call for further analyses to understand geographic variation, cause-specific deaths, location of death, and age-specific trends in CVD mortality [3, 7]. Indeed, whether national trends in CVD mortality extend to a state with historically favorable health trends like the state of Minnesota $(\mathrm{MN})$ is yet to be determined [8]. This is particularly important to plan local interventions. Therefore, we undertook this study to examine trends in CVD death from 2000 to 2018, overall and by age, sex, type of CVD and location of death, in the state of MN.

\section{Methods}

Cardiovascular mortality rates from 2000 to 2018 for the US and MN were obtained using the Centers for Disease Control and Prevention (CDC) Wide-Ranging ONline Data for Epidemiologic Research (WONDER) data set. This data source includes the assigned cause of death from all death certificates filed in the 50 states and the District of Columbia [9]. Underlying cause of death was categorized using ICD 10 codes for all CVD (I00-I99) deaths. Rates are available overall and by demographic subgroups (age and sex), CVD death subgroups (coronary heart disease (CHD), cerebrovascular disease, rhythm disorders, HF and cardiomyopathy, valvular disease, peripheral artery disease (PAD), venous thromboembolism (VTE), high blood pressure, and other), location (in-or out-of-hospital) and residence (urban vs. rural) at death.
Behavioral Risk Factor Surveillance System (BRFSS) data for $\mathrm{MN}$ was ascertained for self-reported obesity (body mass index, $\geq 30$ ) among adults aged 18 and older [10]. The BRFSS is a state-based system of health surveys collecting information on health risk behaviors, preventive health practices, and health care access primarily related to chronic disease, and injury. The US Diabetes Surveillance System, an interactive web application that allows users to view diabetes surveillance data and trends at national, state, and county levels [11], was used to obtain self-reported diabetes mellitus (type 1 and 2) among adults aged 18 and older. This study was exempt from Institutional Review Board approval because all data were de-identified and publicly available.

\section{Statistical analyses}

Yearly number of deaths and population counts, overall and by sex, age (3 categories: 25-64, 65-84, 85+), type of CVD death, location of death, and residence at death, were obtained among those aged 25 and older. Crude and age-adjusted (to the US 2010 population) yearly rates were also obtained except for rates by age groups where only crude rates were available. Overall and category-specific temporal trends in yearly death rates for the time periods 2000-2009 and 2010-2018, which correspond to time periods used in previous work [3], were explored using negative binomial regression, which enables estimates of sex- and age-adjusted (as appropriate) average annual percent changes (AAPCs). Differences in AAPCs between 2000 and 2009 and 2010-2018 were tested overall and across demographics, type of CVD death, and location of death categories. When examining trends by type of CVD death, due to the small number of deaths in certain groups, an 'other CVD' category was created that included, but was not limited to, rhythm disorders, valvular disease, PAD, VTE, high blood pressure. For all categories except age, age was adjusted for in the model as a categorical variable (25-64, 65-84, and $\geq 85$ ). Analyses were performed using SAS statistical software, version 9.4 (SAS Institute Inc., Cary, NC).

\section{Results}

CVD mortality rates in MN declined in 2000-2009 and leveled off in 2010-2018, paralleling national rates (Fig. 1). The overall CVD mortality rate per 100,000 was 346 in 2000-2009 and it declined to 270 in 2010-2018 (Table 1). Age- and sex-adjusted CVD mortality decreased by $3.7 \%$ per year in 2000-2009 (AAPC: -3.7; 95\% CI: $-4.8,-2.6)$ with no change observed in 20102018 (AAPC: 0.0; 95\% CI: - 1.5, 1.5; Table 1). Men had a higher rate of CVD mortality than women; however both groups had a similar decline in the rate of CVD mortality in 2000-2009 with no further improvement in 2010- 


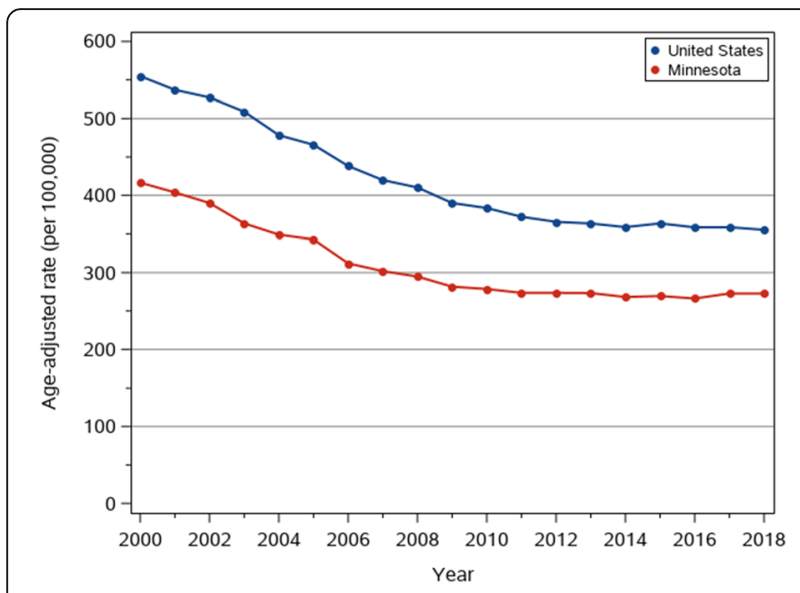

Fig. 1 Trends in total cardiovascular mortality for United States and Minnesota, 2000-2018. Yearly rates per 100,000 persons have been standardized by the direct method to the age distribution of the U.S. 2010 total population
2018 (Table 1). The rate of CVD mortality increased with age (Table 1), however those aged 65-84 had the most rapid decline in CVD mortality from 2000 to 2009 (AAPC: $-5.9,95 \% \mathrm{CI}:-6.2,-5.7$ ), with a slowing of decline in 2010-2018 (AAPC: -1.8, 95\% CI: - 2.2, - 1.5; Table 1). Those in the youngest (age 25-64) and oldest (age 85+) age groups also had a decrease in CVD mortality in 2000-2009 (Table 1). While those aged 85+ showed no change in CVD mortality in 2010-2018 (AAPC: $0.2,95 \%$ CI: - 0.1, 0.5), those aged 25-64 experienced an increase (AAPC: 1.2, 95\% CI: 0.7, 1.8).

The largest proportion of CVD deaths was attributed to CHD (Fig. 2; 43\% of CVD deaths in 2000-2009 and $37 \%$ in 2010-2018), followed by cerebrovascular disease (21 and $20 \%$ of CVD deaths, respectively) and HF/cardiomyopathy (12 and 13\% of CVD deaths, respectively). $\mathrm{CHD}$ and cerebrovascular disease had the largest relative decreases in mortality in 2000-2009. Age- and sexadjusted CHD mortality decreased by $5.2 \%$ per year in 2000-2009 (Table 1, AAPC: -5.2; 95\% CI: - 6.5, - 3.9) with no change 2010-2018. Cerebrovascular disease decreased by $4.4 \%$ (AAPC 95\% CI: - 5.2, - 3.6) per year in 2000-2009 and levelled off thereafter. HF/

Table 1 Cardiovascular disease mortality rates ${ }^{\mathrm{a}}$ (95\% Cls) and average annual percent change (AAPC) ${ }^{\text {b }}$ (95\% Cls) in cardiovascular disease mortality rates among Minnesota residents from 2000 to 2018

\begin{tabular}{|c|c|c|c|c|}
\hline \multirow[t]{3}{*}{ Population } & \multicolumn{4}{|l|}{ Time Period } \\
\hline & \multicolumn{2}{|l|}{$2000-2009$} & \multicolumn{2}{|l|}{$2010-2018$} \\
\hline & Rate & AAPC & Rate & AAPC \\
\hline Overall & $346(344-348)$ & $-3.7(-4.8$ to -2.6$)$ & $270(269-272)$ & $0.0(-1.5$ to +1.5$)$ \\
\hline \multicolumn{5}{|l|}{ Demographic Subgroups } \\
\hline Male & $421(418-425)$ & $-3.7(-4.5$ to -2.9$)$ & $329(326-332)$ & $-0.1(-1.2$ to +1.1$)$ \\
\hline Female & $288(286-291)$ & $-3.8(-4.8$ to -2.9$)$ & $221(219-223)$ & $+0.1(-1.2$ to +1.3$)$ \\
\hline Age 25-64 & $58(57-59)$ & $-1.1(-1.5$ to -0.7$)$ & $57(56-58)$ & $+1.2(+0.7$ to +1.8$)$ \\
\hline Age $65-84$ & $894(886-902)$ & $-5.9(-6.2$ to -5.7$)$ & $594(588-600)$ & $-1.8(-2.2$ to -1.5$)$ \\
\hline Age $85+$ & $5482(5435-5529)$ & $-3.6(-3.8$ to -3.4$)$ & $4572(4531-4613)$ & $+0.2(-0.1$ to +0.5$)$ \\
\hline \multicolumn{5}{|l|}{ CVD Categories } \\
\hline CHD & $149(147-150)$ & $-5.2(-6.5$ to -3.9$)$ & $103(101-104)$ & $-1.3(-3.0$ to +0.5$)$ \\
\hline Cerebrovascular Disease & $73(72-74)$ & $-4.4(-5.2$ to -3.6$)$ & $54(53-54)$ & $-0.6(-1.7$ to +0.5$)$ \\
\hline Cardiomyopathy and Heart Failure & $41(41-42)$ & $-2.5(-3.5$ to -1.5$)$ & $34(34-35)$ & $-0.5(-1.8$ to +0.8$)$ \\
\hline Other $C V D^{c}$ & $83(82-84)$ & $-1.6(-2.7$ to -0.5$)$ & $79(79-81)$ & $+1.9(+0.5$ to +3.3$)$ \\
\hline \multicolumn{5}{|l|}{ Location of Death } \\
\hline In-hospital & $110(109-111)$ & $-4.5(-5.3$ to -3.8$)$ & $74(73-75)$ & $-1.4(-2.5$ to -0.4$)$ \\
\hline Out-of-hospital & 237 (235-238) & $-3.3(-4.7$ to -1.9$)$ & $196(195-198)$ & $+0.4(-1.5$ to +2.4$)$ \\
\hline \multicolumn{5}{|l|}{ Residence at death } \\
\hline Rural & $384(381-388)$ & $-3.3(-4.5$ to -2.1$)$ & $311(307-314)$ & $+0.3(-1.3$ to +1.9$)$ \\
\hline Urban & $326(323-328)$ & $-3.8(-5.0$ to -2.7$)$ & $255(253-257)$ & $+0.1(-1.4$ to +1.7$)$ \\
\hline
\end{tabular}

${ }^{a}$ Yearly rates $(95 \% \mathrm{Cls})$ per 100,000 persons have been standardized by the direct method to the age distribution of the U.S. 2010 total population

${ }^{\mathrm{b}}$ Adjusted for age, and sex. Models stratified by sex were adjusted for age; models stratified by age group were adjusted for sex

All $P$ values $\leq 0.05$ for difference in AAPC between 2000 and 2009 and 2010-2018

CHD coronary heart disease; CVD cardiovascular disease

' Other CVD included, but was not limited to, rhythm disorders, valvular disease, PAD, VTE, and high blood pressure 


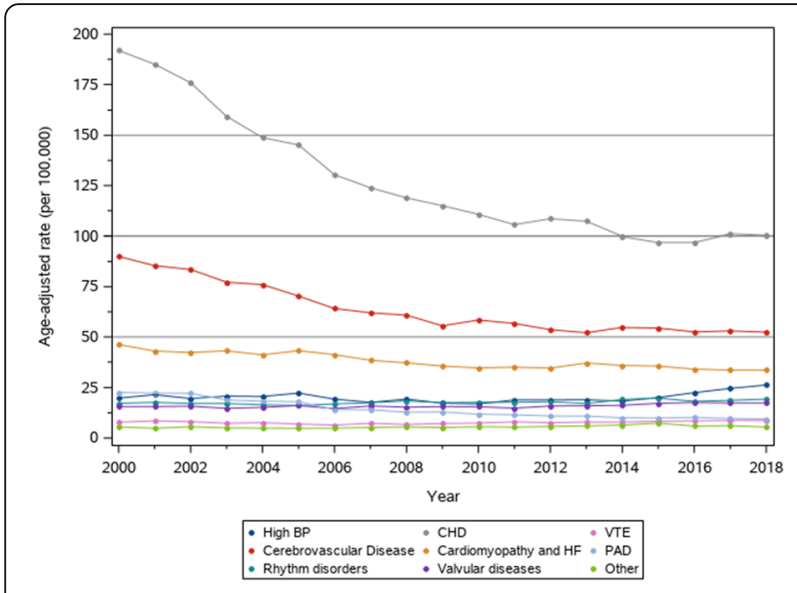

Fig. 2 Trends in cardiovascular mortality subtypes for Minnesota, 2000-2018. Yearly rates per 100,000 persons have been standardized by the direct method to the age distribution of the U.S. 2010 total population

BP blood pressure; CHD coronary heart disease; HF heart failure; PAD peripheral artery disease; VTE: venous thromboembolism

cardiomyopathy followed similar trends with a $2.5 \%$ (AAPC 95\% CI: - 3.5, - 1.5) decrease per year in 20002009 and no change in 2010-2018. Deaths from other CVD also decreased in the early time period (AAPC: -1.6, 95\% CI: $-2.7,-0.5)$ but increased in 2010-2018 (AAPC: 1.9, 95\% CI: 0.5, 3.3). In- and out-of-hospital CVD death rates improved in 2000-2009 with a slowing in improvement for in-hospital death and no further improvement for out-of-hospital death in 2010-2018 (Table 1). CVD death rates improved for both rural and urban residents from 2000 to 2009, however the rates leveled off in 2010-2018 (Table 1).

In $\mathrm{MN}$ between 1995 and 2018, the prevalence of diabetes mellitus and obesity increased among adults aged 18 and over (Fig. 3). The prevalence of obesity doubled over the study period, increasing from 15\% in 1995 to $30 \%$ in 2018 and the prevalence of diabetes more than doubled, increasing from 3.1\% in 1995 to $7.6 \%$ in 2016 (data not available after 2016).

\section{Discussion}

In $\mathrm{MN}, \mathrm{CVD}$ mortality trends have become quite unfavorable. In the earlier time period, CHD and cerebrovascular disease mortality rates had the largest decreases, but most recently mortality from all CVD subtypes plateaued or even increased. Mortality among the younger age groups increased as well. These data are congruent with recent national reports that CVD mortality in the US no longer follows the favorable decline observed since the mid-1960s [3, 7]. An analysis of deaths from ischemic heart disease, HF and other forms of heart disease uncovered that this national evolution was driven by increases in deaths related to HF and other forms of heart diseases [7]. Herein, we report that these unfavorable trends apply to MN, which had been historically ranked one of the top 10 healthiest states since 1990 according to America's Health Rankings [8]. Although reports suggest that 30 -day mortality rates after hospitalized MI have been declining [12, 13] and evidence-based treatment for MI has been increasing $[14,15]$, many CVD risk factors are also increasing. Obesity is prevalent [10] and diabetes mellitus rates are increasing, [11] and hypertension control is worsening [6], likely contributing to the slowing in decline of CVD mortality.

While the unfavorable CVD mortality trends are a concern in the US, in Europe recent mortality data do not support such a concern [16]. Available data from six European populations indicate that from 1985 to 2010 acute MI mortality decreased [17] and similarly, decreased from 2001 to 2014 in Norway [18], while in France CHD mortality decreased overall from 2006 to 2014 [19]. Adverse trends in risk factors, such as diabetes and obesity [4, 5], could however unfortunately

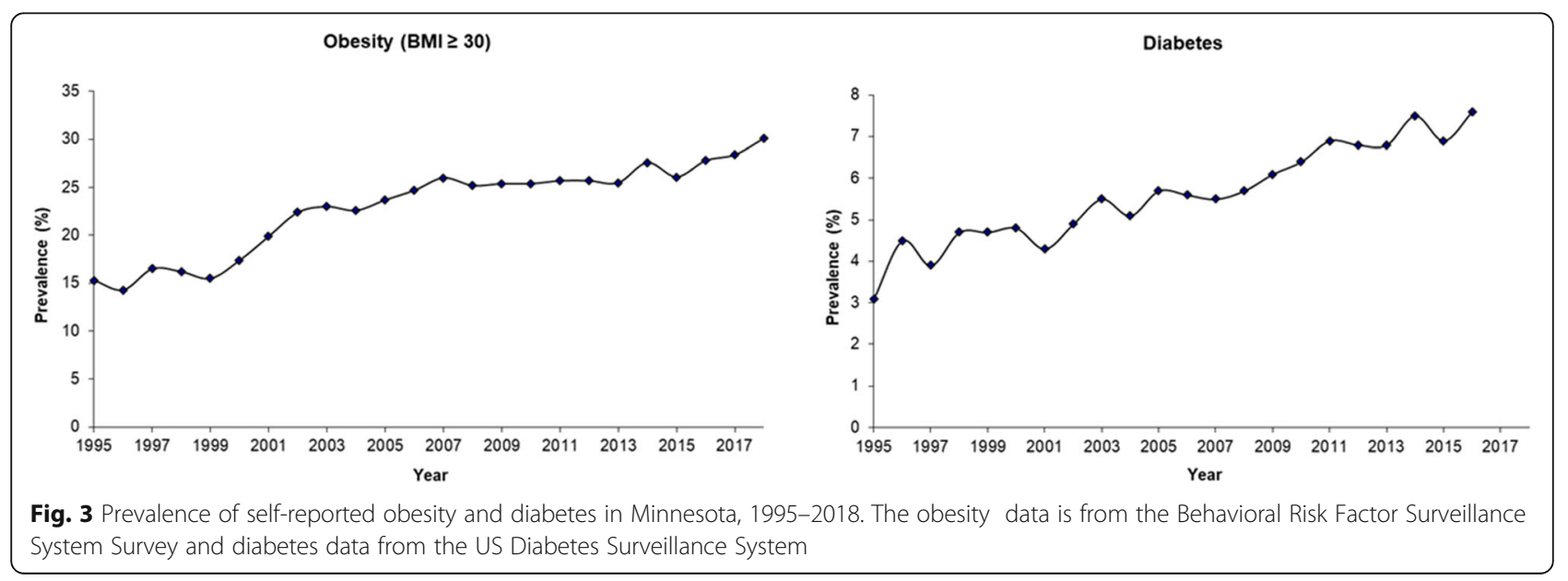


lead to unfavorable CVD mortality trends as is currently observed in MN and the US.

While the trends in CVD mortality in MN did not differ by sex, they did so by age. Indeed, in recent years (2010-2018), CVD deaths increased among younger adults (age 25-64), a finding which is congruent with other reports [20-23]. Reasons for this unfavorable trend may include an increase in myocardial infarction incidence and in the prevalence of CVD risk factors among younger adults $[21,23,24]$.

Furthermore, we found that while there was a decline in deaths in all of the CVD subtypes in the earlier time period, deaths from CHD, cerebrovascular disease, and cardiomyopathy/HF no longer declined in the most recent decade (2010-2018), possibly reflecting the increase in obesity and diabetes observed over the same period $[10,11]$. Indeed these are all major risk factors for CHD, stroke, and HF [1]. It is notable that deaths in the other CVD category experienced an increase in recent years. However, because this group is heterogeneous it is difficult to draw conclusions, and this finding warrants further study. Taken collectively, these observations and the evidence that deaths from all CVD subtypes have either plateaued or increased, underscores the need for continued surveillance and emphasis on prevention and treatment of these conditions.

We also investigated location of death (in- vs. out-ofhospital) and residence at death (urban vs. rural). Inand out-of-hospital death rates improved in earlier years (2000-2009) with a slowing in improvement for inhospital death and no further improvement for out-ofhospital death in recent years (2010-2018). Finally, CVD death rates initially improved for both urban and rural residents; however the rates leveled off in the recent time period.

We acknowledge that CDC WONDER data is codebased and subject to coding errors and although ICD-10 coding of the underlying cause of death was used the entire study period, we cannot rule out that changes in coding rules may have occurred. WONDER data also relies on underlying cause of death and we do not have information on other contributing factors of death. However, by using this national data source we can directly compare our results to the US overall and to other states. Our results emanate from the state of $\mathrm{MN}$ which has historically experienced favorable health rankings and is currently ranked the 7th healthiest state in the US [8]. Further, overall age- and sex-specific mortality trends are similar for MN and the entire US, and broad disease trends in $\mathrm{MN}$ are commensurate to national trends [25], supporting the broad relevance of our data.

We not only investigated overall trends in CVD mortality, but also investigated trends by age, sex, type of CVD, and location and residence at death. Furthermore, our report establishes CVD mortality trends prior to the coronavirus (COVID-19) pandemic. Recent reports in the US have indicated that hospitalizations for myocardial infarction as well as ST-segment elevation cardiac catheterizations have declined significantly since the COVID-19 pandemic began in early 2020 [26, 27]. In addition, the change in healthcare delivery due to COVID-19 may have impacted patients with HF [28, 29], and indeed a recent report from Denmark has indicated that the number of patients hospitalized with worsening $\mathrm{HF}$ or diagnosed with new-onset HF was reduced post COVID-19 [30]. The impact of COVID-19 on CVD mortality in the US will need to be studied, as one can hypothesize that it will have a substantial effect on trends. The present data serve to document the trends before the beginning of the pandemic.

\section{Conclusion}

In MN, the CVD mortality rates are no longer declining, paralleling national trends. CHD and cerebrovascular disease mortality rates had the largest early (2000-2009) decreases. In the most recent decade (2010-2018) mortality from all CVD subtypes plateaued or even increased. Mortality among younger age groups increased as well. These findings call for renewed emphasis on CVD prevention and treatment, including local interventions. Continued surveillance will be critical to assess progress.

\section{Abbreviations}

AAPC: Average annual percent changes; BP: Blood pressure;

BRFSS: Behavioral Risk Factor Surveillance System; CDC: U.S. Centers for Disease Control and Prevention; CHD: Coronary heart disease; Cl: Confidence interval; CVD: Cardiovascular disease; HF: Heart failure; MI: Myocardial Infarction; MN: Minnesota; PAD: Peripheral artery disease; US: United States; VTE: Venous thromboembolism; WONDER: Wide-ranging ONline Data for Epidemiologic Research

Acknowledgements

We thank Ellen Koepsell and Deborah Strain for their valuable support.

\section{Authors' contributions}

SM and VR had full access to all the data in the study and take responsibility for the integrity of the data and the accuracy of the data analysis. JK and SW conducted the data analysis. Substantial contributions to conception or design of the work, or the acquisition, analysis, or interpretation of data for the work: SM, YG, SB, AC, KM, SW, JK, and VR. Drafting of the work or revising it critically for important intellectual content: SM, YG, SB, AC, KM, SW, JK, and VR. Final approval of the version to be published: SM, YG, SB, AC, KM, SW, JK, and VR. Agreement to be accountable for all aspects of the work in ensuring that questions related to the accuracy or integrity of any part of the work are appropriately investigated and resolved: SM and VR. All authors have read and approved the final manuscript.

\section{Funding}

This study was supported by the National Institutes of Health, Bethesda, MD (R01 HL120957). The funding sources played no role in the design, conduct, or reporting of this study. 


\section{Availability of data and materials}

The source of the mortality data for this study was the U.S. Centers for Disease Control and Prevention (CDC) Wide-ranging ONline Data for Epidemiologic Research (WONDER). https://wonder.cdc.gov/

The obesity prevalence data was obtained from the CDC Behavioral Risk Factor Surveillance System (BRFSS). https://www.cdc.gov/brfss/ brfssprevalence/

The diabetes prevalence data was obtained from the CDC United States Diabetes Surveillance System. https://gis.cdc.gov/grasp/diabetes/ DiabetesAtlas.html

\section{Declarations}

\section{Ethics approval and consent to participate}

This study was exempt from Institutional Review Board approval because all data were de-identified and publicly available.

\section{Consent for publication}

Not applicable.

\section{Competing interests}

The authors declare that they have no competing interests.

\section{Author details}

'Department of Quantitative Health Sciences, Mayo Clinic, 200 First Street, SW, Rochester, MN 55905, USA. ${ }^{2}$ Department of Epidemiology and Preventive Medicine, School of Public Health, Sackler Faculty of Medicine, Tel Aviv University, Tel Aviv, Israel. ${ }^{3}$ HealthPartners Institute, Minneapolis, MN, USA. ${ }^{4}$ Department of Cardiovascular Diseases Medicine, Mayo Clinic, Rochester, MN, USA. ${ }^{5}$ Epidemiology and Community Health Branch, National Heart, Lung and Blood Institute, National Institutes of Health, Bethesda, MD, USA.

Received: 22 December 2020 Accepted: 17 May 2021

Published online: 01 June 2021

\section{References}

1. Virani SS, Alonso A, Benjamin EJ, Bittencourt MS, Callaway CW, Carson AP, et al. Heart disease and stroke Statistics-2020 update: a report from the American Heart Association. Circulation. 2020;141(9):e139-596. https://doi. org/10.1161/CIR.0000000000000757.

2. Mensah GA, Wei GS, Sorlie PD, Fine LJ, Rosenberg Y, Kaufmann PG, et al. Decline in cardiovascular mortality: possible causes and implications. Circ Res. 2017;120(2):366-80. https://doi.org/10.1161/CIRCRESAHA.116.309115.

3. Sidney S, Quesenberry CP Jr, Jaffe MG, Sorel M, Nguyen-Huynh MN, Kushi $\mathrm{LH}$, et al. Recent trends in cardiovascular mortality in the United States and public health goals. JAMA Cardiol. 2016;1(5):594-9. https://doi.org/10.1001/ja macardio.2016.1326.

4. Di Cesare M, Bentham J, Stevens GA, Zhou B, Danaei G, Lu Y, et al. Trends in adult body-mass index in 200 countries from 1975 to 2014: a pooled analysis of 1698 population-based measurement studies with 19.2 million participants. Lancet. 2016:387:1377-96.

5. Zhou B, Lu Y, Hajifathalian K, Bentham J, Di Cesare M, Danaei G, et al. Worldwide trends in diabetes since 1980: a pooled analysis of 751 population-based studies with 4.4 million participants. Lancet. 2016;387: 1513-30.

6. Muntner P, Hardy ST, Fine $L$, Jaeger BC, Wozniak G, Levitan EB, et al. Trends in blood pressure control among US adults with hypertension, 1999-2000 to 2017-2018. JAMA. 2020;324(12):1 190-200. https://doi.org/10.1001/jama.202 0.14545 .

7. Sidney S, Quesenberry CP Jr, Jaffe MG, Sorel M, Go AS, Rana JS. Heterogeneity in national U.S. mortality trends within heart disease subgroups, 2000-2015. BMC Cardiovasc Disord. 2017;17(1):192.

8. America's Health Rankings United Health Foundation. Accessed at: https:// www.americashealthrankings.org/ on Jul 8, 2020.

9. CDC WONDER. Centers for Disease Control and Prevention. Accessed at: https://wonder.cdc.gov/ on Jul 8, 2020.

10. BRFSS Prevalence \& Trends Data. Centers for Disease Control and Prevention, National Center for Chronic Disease Prevention and Health Promotion, Division of Population Health. Accessed at: https://www.cdc. gov/brfss/brfssprevalence/ on Nov 18, 2020.
11. United States Diabetes Surveillance System. Centers for Disease Control and Prevention (CDC). Accessed at: https://gis.cdc.gov/grasp/diabetes/DiabetesA tlas.html on November 18, 2020.

12. Krumholz HM, Normand ST, Wang Y. Twenty-year trends in outcomes for older adults with acute myocardial infarction in the United States. JAMA Netw Open. 2019;2(3):e191938. https://doi.org/10.1001/jamanetworkopen.2 019.1938.

13. Rosamond WD, Chambless LE, Heiss G, Mosley TH, Coresh J, Whitsel E, et al. Twenty-two-year trends in incidence of myocardial infarction, coronary heart disease mortality, and case fatality in 4 US communities, 1987-2008. Circulation. 2012;125(15):1848-57. https://doi.org/10.1161/CIRCULATIONA HA.111.047480.

14. O'Brien EC, Rose KM, Suchindran CM, Sturmer T, Chang PP, Alonso A, et al. Temporal trends in medical therapies for ST- and non-ST elevation myocardial infarction: (from the atherosclerosis risk in communities [ARIC] surveillance study). Am J Cardiol. 2013;111(3):305-11. https://doi.org/10.101 6/j.amjcard.2012.09.032.

15. Virani SS, Alonso A, Aparicio HJ, Benjamin EJ, Bittencourt MS, Callaway CW, et al. Heart disease and stroke Statistics-2021 update: a report from the American Heart Association. Circulation. 2021;143(8):e254-743. https://doi. org/10.1161/CIR.0000000000000950.

16. Timmis A, Townsend N, Gale CP, Torbica A, Lettino M, Petersen SE, et al. European Society of Cardiology: cardiovascular disease statistics 2019. Eur Heart J. 2020;41(1):12-85. https://doi.org/10.1093/eurheartj/ehz859.

17. Dégano IR, Salomaa V, Veronesi G, Ferriéres J, Kirchberger I, Laks T, et al. Twenty-five-year trends in myocardial infarction attack and mortality rates, and case-fatality, in six European populations. Heart. 2015;101(17):1413-21. https://doi.org/10.1136/heartjnl-2014-307310.

18. Sulo G, Igland J, Vollset SE, Ebbing M, Egeland GM, Ariansen I, et al. Trends in incident acute myocardial infarction in Norway: an updated analysis to 2014 using national data from the CVDNOR project. Eur J Prev Cardiol. 2018; 25(10):1031-9. https://doi.org/10.1177/2047487318780033.

19. Meirhaeghe A, Montaye M, Biasch K, Huo Yung Kai S, Moitry M, Amouyel P, et al. Coronary heart disease incidence still decreased between 2006 and 2014 in France, except in young age groups: results from the French MONICA registries. Eur J Prev Cardiol. 2020;27(11):1178-86. https://doi.org/1 $0.1177 / 2047487319899193$

20. Arora S, Stouffer GA, Kucharska-Newton AM, Qamar A, Vaduganathan M, Pandey A, et al. Twenty year trends and sex differences in young adults hospitalized with acute myocardial infarction. Circulation. 2019;139(8):104756. https://doi.org/10.1161/CIRCULATIONAHA.118.037137.

21. Ritchey MD, Wall HK, George MG, Wright JS. US trends in premature heart disease mortality over the past 50 years: where do we go from here? Trends Cardiovasc med; 2019.

22. Wilmot KA, O'Flaherty M, Capewell S, Ford ES, Vaccarino V. Coronary heart disease mortality declines in the United States from 1979 through 2011: evidence for stagnation in young adults, especially women. Circulation. 2015;132(11):997-1002. https://doi.org/10.1161/CIRCULA TIONAHA.115.015293.

23. Ford ES, Capewell S. Coronary heart disease mortality among young adults in the U.S. from 1980 through 2002: concealed leveling of mortality rates. J Am Coll Cardiol. 2007;50(22):2128-32. https://doi.org/1 0.1016/j.jacc.2007.05.056.

24. Awad HH, McManus DD, Anderson FA Jr, Gore JM, Goldberg RJ. Young patients hospitalized with an acute coronary syndrome. Coron Artery Dis. 2013;24(1):54-60. https://doi.org/10.1097/MCA.0b013e32835b0bf7.

25. St Sauver JL, Grossardt BR, Yawn BP, Melton LJ 3rd, Pankratz JJ, Brue SM, et al. Data resource profile: the Rochester epidemiology project (REP) medical records-linkage system. Int J Epidemiol. 2012;41(6):1614-24. https:// doi.org/10.1093/ije/dys195.

26. Garcia S, Albaghdadi MS, Meraj PM, Schmidt C, Garberich R, Jaffer FA, et al. Reduction in ST-segment elevation cardiac catheterization laboratory activations in the United States during COVID-19 pandemic. J Am Coll Cardiol. 2020;75(22):2871-2. https://doi.org/10.1016/j.jacc.2020.04.011.

27. Solomon MD, McNulty EJ, Rana JS, Leong TK, Lee C, Sung SH, et al. The Covid-19 pandemic and the incidence of acute myocardial infarction. N Engl J Med. 2020 [Epub ahead of print];383(7):691-3. https://doi.org/10.1 056/NEJMc2015630.

28. DeFilippis EM, Reza N, Donald E, Givertz MM, Lindenfeld J, Jessup M. Considerations for heart failure care during the COVID-19 pandemic. JACC: Heart Fail. 2020;8(8):681-91. https://doi.org/10.1016/j.jchf.2020.05.006. 
29. Reza N, DeFilippis EM, Jessup M. Secondary impact of the COVID-19 pandemic on patients with heart failure. Circ Heart Fail. 2020;13(5):e007219. https://doi.org/10.1161/CIRCHEARTFAILURE.120.007219.

30. Andersson C, Gerds T, Fosbøl E, Phelps M, Andersen J, Lamberts M, et al. Incidence of new-onset and worsening heart failure before and after the COVID-19 epidemic lockdown in Denmark: a Nationwide cohort study. Circ Heart Fail. 2020;13(6):e007274. https://doi.org/10.1161/CIRCHEARTFAlLURE.12 0.007274

\section{Publisher's Note}

Springer Nature remains neutral with regard to jurisdictional claims in published maps and institutional affiliations.

Ready to submit your research? Choose BMC and benefit from:

- fast, convenient online submission

- thorough peer review by experienced researchers in your field

- rapid publication on acceptance

- support for research data, including large and complex data types

- gold Open Access which fosters wider collaboration and increased citations

- maximum visibility for your research: over $100 \mathrm{M}$ website views per year

At BMC, research is always in progress.

Learn more biomedcentral.com/submissions 